\title{
Design of Arm \& L-bracket and It's Optimization By Using Taguchi Method
}

\author{
S. F.Sakore, K. A. Mahajan \\ (Department of Mechanical Engineering, M. E. S. College of Engineering, S. P. Pune University, India)
}

\begin{abstract}
In industries it is required to assemble the structures like pressure vessel on overhead positions. This process needs lifting devices to reach up to working location. To assemble such structures, various joining operations need to be performed such as welding in overhead position. This work includes the redesign of existing lifting platform system with tilting joint so that the operations can be performed easily and more efficiently. In short the square shaped platform changed with semicircular shape platform and accordingly changing parameters are validated. Solution to cover more radial distance for operation on pressure vessels outer surface with load calculations and boundary conditions also working of tilting arm is validated with stresses and deflection coming on titling joints. Also structural behavioral results are compared and validated.

Keyword - FEA, Johnson Method, Lifting Arm, L-Bracket, Optimum Design, Taguchi Method
\end{abstract}

\section{INTRODUCTION}

In assembly of pressure vessels, the joining processes/welding are performed on top head position which becomes too hectic and less efficient. The current system includes a standing cage from where the operator performs these operations. But due to the less width of the cage and improper design of the cage very less area of pressure vessel is worked (as the vessel is cylindrical in shape). This work includes the redesign of the system and its validation. A new system design is proposed with proper shape and size of standing cage. For required movement of the cage, the cage is attached to be with pivot joint. The lift of the cage is hydraulically operated. [1]

\section{PROBLEM STATEMENT}

In the current system as shown in Fig.1, it is observed that due to the shape and size of the standing cage, it becomes difficult for operator to weld / join maximum area of pressure vessel. Need to replace square platform into semicircular platform. Hence, a system with proper standing cage needs to be redesign so that maximum area of pressure vessel can be operated. Tilting is to be made with L bracket and tilting joints.

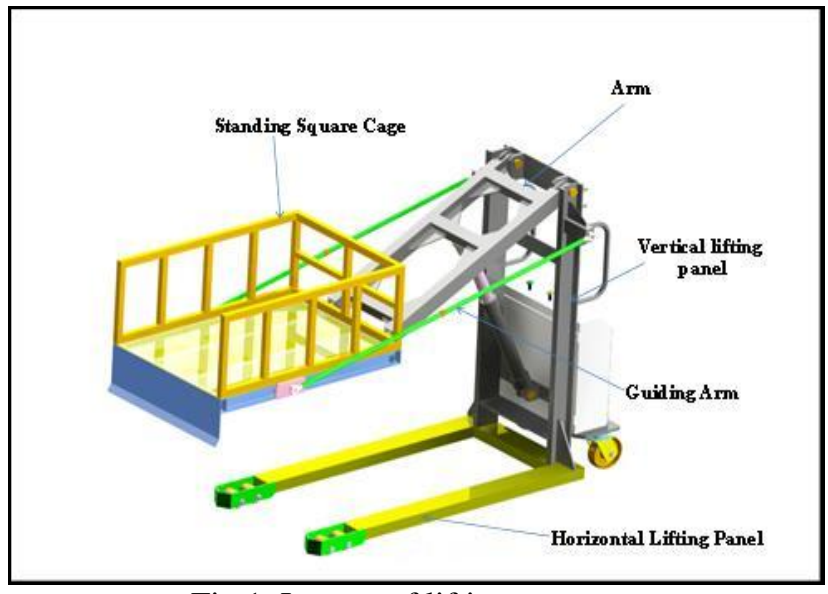

Fig.1. Layout of lifting structure

\section{THEROTICAL DESIGN}

3.1 Design of Semicircular Platform:

In this work, existing square platform is replaced by semi-circular platform. New platform development as shown in Fig. 2 is carried out with the dimensions of bigger pressure vessel size of diameter i.e., 
$1750 \mathrm{~mm}$. So here we consider $1800 \mathrm{~mm}$ of platform internal diameter and $50 \mathrm{~mm}$ clearance between working object and lifting assembly should be there. [2]

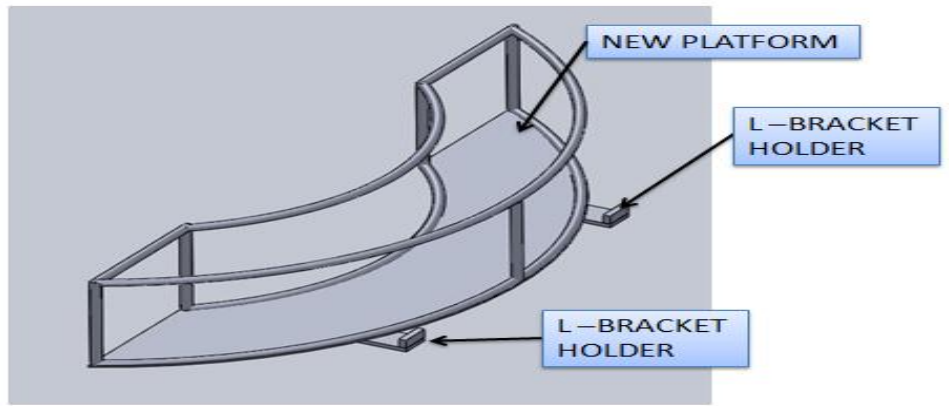

Fig.2. CAD model of semi-circular platform

3.2 Tilting Joint design:

In this design, hollow strut is used to lift maximum load of $5000 \mathrm{~kg}$ as shown in Fig 3.

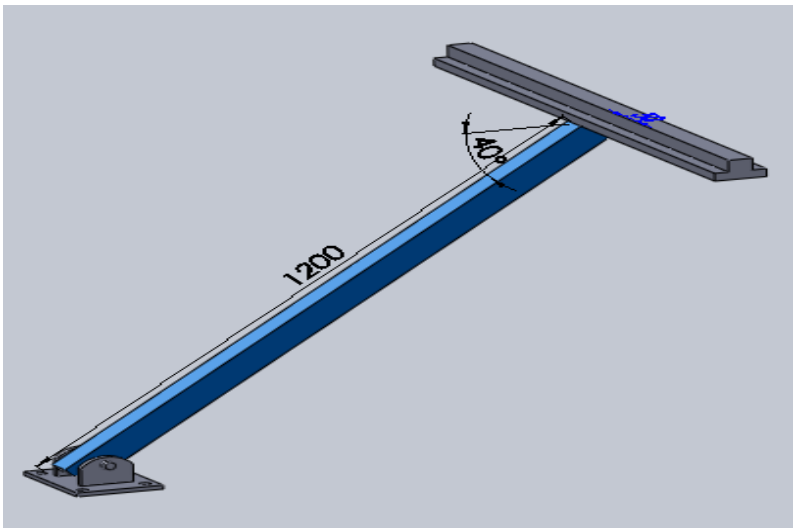

Fig.3. CAD model of lifting arm $\left(40^{\circ}\right.$ tilt $)$

Tilting joint assembly model as shown in Fig.4 and also the CAD model is shown in Fig.5.

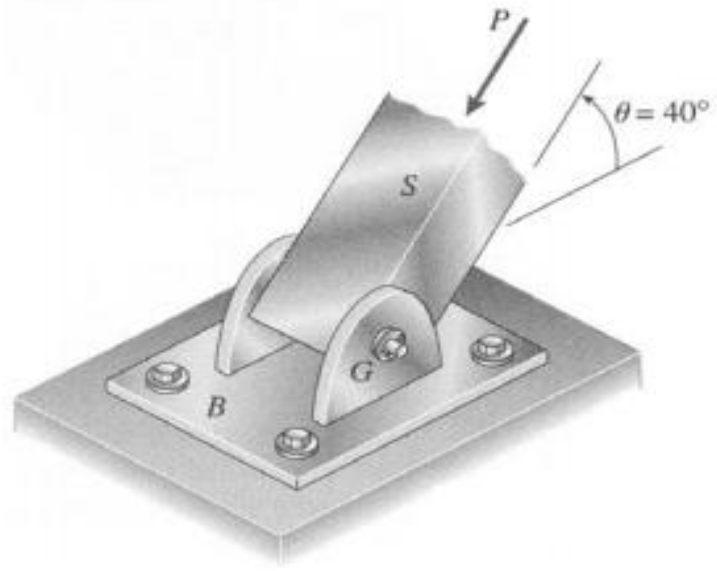

Fig.4. Tilting Joint assembly

Where,

$\mathrm{S}=$ Strut, $\mathrm{G}=$ gusset, $\mathrm{B}=$ Anchor bolts, $\mathrm{P}=\mathrm{Pin}$ 


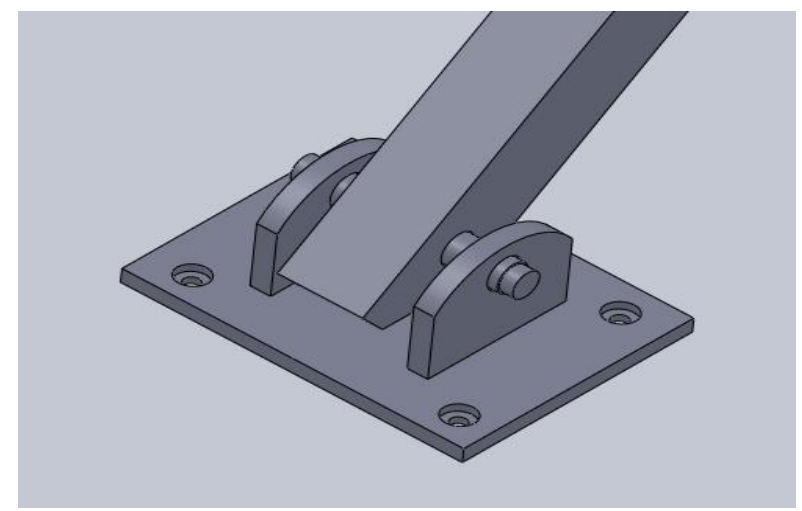

Fig.5. CAD model of tilting Joint assembly

Measured values of the assembly components are shown in Table 1:

Table 1: Dimensions of Components

\begin{tabular}{|l|c|}
\hline \multicolumn{1}{|c|}{ Components } & Value $(\mathrm{mm})$ \\
\hline Thickness of strut, $\mathrm{t}$ & 10 \\
\hline Thickness of gussets, $\mathrm{t}_{\mathrm{G}}$ & 15 \\
\hline Diameter of anchor bolt, $\mathrm{d}_{\mathrm{bolt}}$ & 12 \\
\hline Thickness of base plate, $\mathrm{t}_{\mathrm{B}}$ & 10 \\
\hline Diameter of pin, $\mathrm{d}_{\text {pin }}$ & 20 \\
\hline
\end{tabular}

\subsection{Results: [3]}

- $\quad$ Shear stress in anchor bolts $=84.7 \mathrm{MPa}$

- Bearing Stress between anchor bolts and base plate $=79.8 \mathrm{MPa}$

- Bearing Stress between pin and gussets $=83.3 \mathrm{MPa}$

- Bearing stress between struts and pin $=125 \mathrm{MPa}$

3.4 $\mathrm{L}$ joint lifting behavior:

Due to applied load stress sand deflection generated in the body. CAD model of L-bracket is as shown in Fig.6.

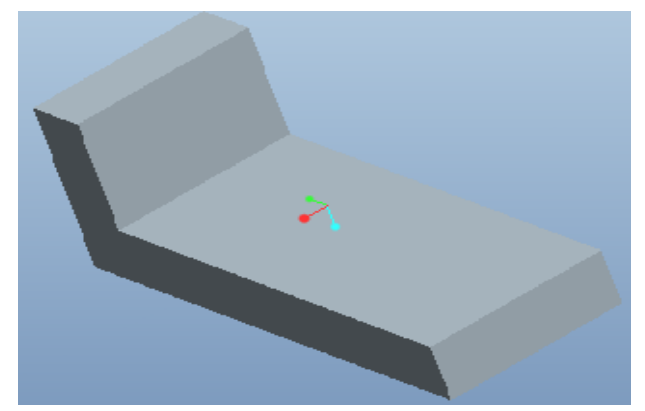

Fig.6. CAD model of L-Bracket [3]
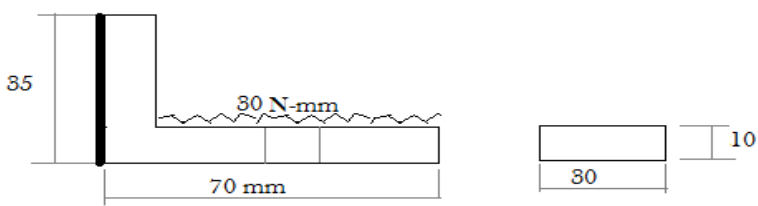

Fig.7. FBD of L-Bracket [3]

Hence,

As seen from the FBD as shown in Fig.7, 
Maximum bending moment, $\mathrm{M}=73500 \mathrm{~N}-\mathrm{mm}$

Moment of inertia (I) $=2500 \mathrm{~mm}^{4}$

Maximum bending stress developed in the member $=147.00 \mathrm{~N} / \mathrm{mm}^{2}$ and

Maximum deflection of the member $=0.18007 \mathrm{~mm}$

\section{MATERIAL SELECTION}

4.1 Optimum Material Selection by Johnson Method:

Optimum design of mechanical element is the selection of material and values for independent geometrical parameters with explicit objective of either minimizing most significant undesirable effect or maximizing a most significant functional requirement, making in the design procedure that the mechanical element satisfies other functional requirements and that other undesirable effects are kept within tolerable limits. [4]

\subsection{Objective of optimum design:}

For any design problem, varieties of solutions are available. Solution of the problem is performance, cost, safety and robustness requirement etc. These solutions complete this requirement. Now a day, selection of the best available design solution is very important parameter. Optimization techniques are help perfectly to select the best design solution among the available solutions. [4]

In design of any mechanical element, a number of design parameters are used. These design parameters, which are related to each other by number of design equations, can be broadly classified three basic groups.

i) Functional requirement parameters

ii) Material properties

iii) Geometrical parameters

4.3 The geometrical parameters:

$\mathrm{W}=$ weight of plate, $\mathrm{Kg}$

$\mathrm{w}=$ weight density of material, $\mathrm{Kg} / \mathrm{mm}^{3}$

$\mathrm{b}=$ width of plate, $\mathrm{mm}$

$1=$ length of plate, $\mathrm{mm}$

$\mathrm{t}=$ thickness of plate, $\mathrm{mm}$

$\mathrm{K}=$ stiffness of plate

$\sigma_{\mathrm{b}}=$ bending stresses, $\mathrm{N} / \mathrm{mm}^{2}$

$\mathrm{F}=$ applied force, $\mathrm{N}$

$\mathrm{N}_{\mathrm{f}}=$ factor of safety

$\mathrm{S}_{\mathrm{b}}=$ bending strength

$\mathrm{S}_{\mathrm{y}}=$ yield strength

Primary Design Equation (P.D.E):

Weight $(\mathrm{W})$ per unit length $=$ weight density $\times$ volume of plate

$\mathrm{W}=\mathrm{w} \times(\mathrm{b} \times \mathrm{l} \times \mathrm{t})$

Subsidiary design equation (S.D.E):

Bending stress $=\mathrm{F} \times \mathrm{L} \times \mathrm{Y} \times 12 / \mathrm{bt}^{3}$

From Eq. 1 \& 2

$\mathrm{W}=\mathrm{Kx} \mathrm{W} / \mathrm{Sy}^{0.5}$

The properties of the material are as shown in Table 2.

Table 2.Properties of the material

\begin{tabular}{|c|c|c|c|}
\hline Materials & $\begin{array}{c}\text { Weight } \\
\text { Density } \\
\mathrm{W}\end{array}$ & $\begin{array}{c}\text { Yield strength } \\
\mathbf{S}_{\text {y. }}\end{array}$ & $\frac{\mathrm{w}}{\sqrt{S_{\text {. }}}}$ \\
\hline SS 304 & 78480 & 205 & 5481.28 \\
\hline SS 316 & 78480 & 205 & 5481.28 \\
\hline SS 310 & 78744.87 & 210 & 5433.91 \\
\hline SS 309 & 78480 & 325 & 4353.29 \\
\hline
\end{tabular}


From above equation 3, it is possible to evaluate weight density of various steels which directly affects the weight of material. Among above tabulated results, weight factor $\left(\frac{w}{\sqrt{S_{y}}}\right)$ for alloy steel is lower than any other type of steel so it is justified that SS 309 is optimal material for structure assembly.

\section{DESIGN OF EXPERIMENT}

5.1 Introduction:

Design of experiments deals with the planning, conducting, analyzing and interpreting controlled tests to evaluate the factors that control the value of a parameter or group of parameters. The strategically planned and executed experiment may provide a great deal of information about the effect on a response variable due to one or more factors. To reduce the number of experiments to practical level, only a small set from all the possibilities is selected. The method of selecting number of experiments which produces the more information is known as a partial fraction experiment. [5]

\subsection{Taguchi Method:}

Taguchi is the most popular method. Taguchi has established a new method of conducting the design of experiments which are based on well-defined guidelines. This method uses a special set of arrays called as orthogonal arrays. This standard method gives a way for minimising the quantity of performance of the tests. This method gives information about all the influencing parameters which directly or indirectly affects the efficiency or performance. [6]

\subsubsection{Steps involves in Design of experiment:}

1. Selection of independent variables

2. Selection of number of level setting for each independent variable

3. Selection of orthogonal array

4. Assigning the independent variables to each column

5. Conducting the experiments

6. Analysing the data

7. Inference

In case of L- Bracket as shown in Fig.8, length of bracket is $70 \mathrm{~mm}$, width of $30 \mathrm{~mm}$ and thickness of $10 \mathrm{~mm}$.

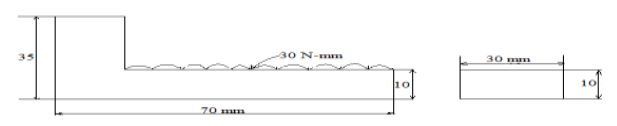

Fig.8 CAD model of L-bracket

Length, width and stresses are three variables. We are selecting the three different types of materials AISI 1018, SS304, AISI 306.

From bending moment equation,

$\frac{\mathrm{M}}{\mathrm{I}}=\frac{\sigma}{\mathrm{y}}$

Where,

$\mathrm{y}=\frac{\mathrm{t}}{2} \& I=\frac{\mathrm{bt}^{3}}{12}$

$\mathrm{t}=\frac{\sqrt{\mathrm{M} \times 6}}{\mathrm{~b} \times \sigma}$

Parameters which are selected are as shown in Table no. 3. 
Table 3: DOE table for the finalization of the design calculations

\begin{tabular}{|c|c|c|c|c|c|c|c|c|}
\hline $\begin{array}{c}\mathbf{W} \\
(\mathbf{N} / \mathbf{m m})\end{array}$ & $\begin{array}{c}\mathbf{L} \\
(\mathbf{m m})\end{array}$ & $\begin{array}{c}\mathbf{M} \\
\mathbf{( N -} \\
\mathbf{m m})\end{array}$ & $\begin{array}{c}\mathbf{b} \\
(\mathbf{m m})\end{array}$ & $\begin{array}{c}\mathbf{t} \\
\mathbf{( m m})\end{array}$ & $\begin{array}{c}\square \\
\text { Sigma } \\
\mathbf{( M P a})\end{array}$ & $\mathbf{F O S}$ & $\begin{array}{c}\text { Yield } \\
\text { Stress } \\
\mathbf{( M P a}\end{array}$ & $\begin{array}{c}\text { Allowable } \\
\text { Stress } \\
(\mathbf{M P a})\end{array}$ \\
\hline 30 & 70 & 73500 & 30 & 10.00 & 147 & 1.5 & 325 & 216.7 \\
\hline 30 & 70 & 73500 & 29 & 9.50 & 168 & 1.5 & 325 & 216.7 \\
\hline 30 & 70 & 73500 & 28 & 9.00 & 194 & 1.5 & 325 & 216.7 \\
\hline 30 & 80 & 96000 & 30 & 9.50 & 213 & 1.5 & 325 & 216.7 \\
\hline 30 & 80 & 96000 & 29 & 9.00 & 245 & 1.5 & 325 & 216.7 \\
\hline 30 & 80 & 96000 & 28 & 10.00 & 206 & 1.5 & 325 & 216.7 \\
\hline 30 & 90 & 121500 & 30 & 9.00 & 300 & 1.5 & 325 & 216.7 \\
\hline 30 & 90 & 121500 & 29 & 10.00 & 251 & 1.5 & 325 & 216.7 \\
\hline 30 & 90 & 121500 & 28 & 9.50 & 288 & 1.5 & 325 & 216.7 \\
\hline
\end{tabular}

\subsection{ANOVA Results: [7]}

Taguchi matrix above shows the results for the design selection of the bracket on the basis of strength. ANOVA is performed below to select the optimum solution for the bracket design.

In the Fig.9, it is observed that, the thickness of the L-bracket is $10 \mathrm{~mm}$ at the length of $70 \mathrm{~mm}$.

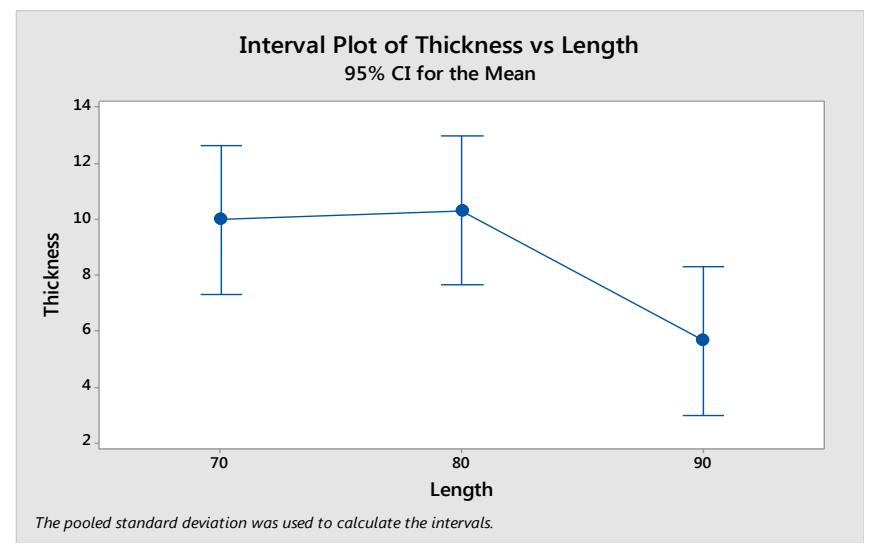

Fig.9. Main effect plot of Length vs Thickness

In the Fig.10, it is observed that, the thickness of the L-bracket is $10 \mathrm{~mm}$ at the width is $30 \mathrm{~mm}$.

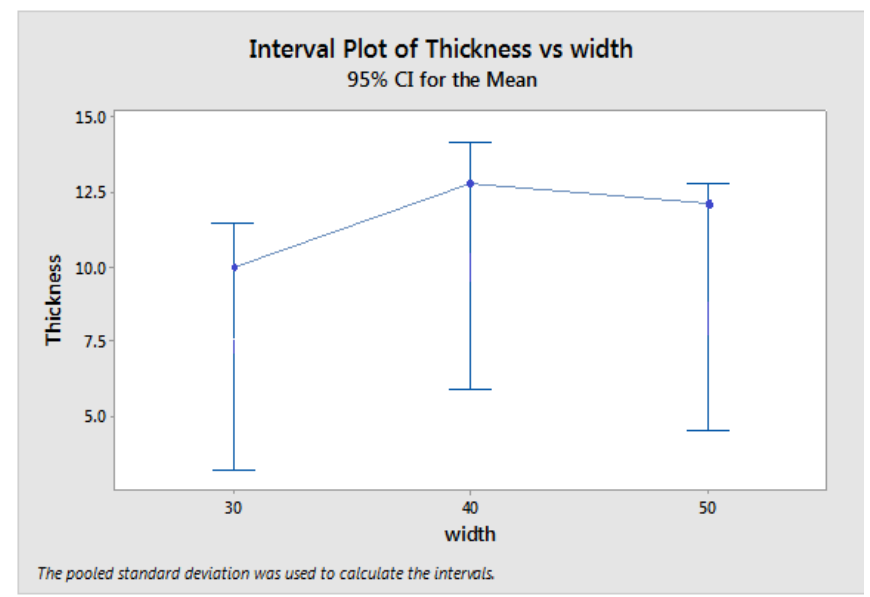

Fig.10 Main effect plot of Width vs Thickness 
In the Fig.11, it is observed that, the thickness of the L-bracket is $10 \mathrm{~mm}$ stresses in the range of $200 \mathrm{MPa}$ to $300 \mathrm{MPa}$.

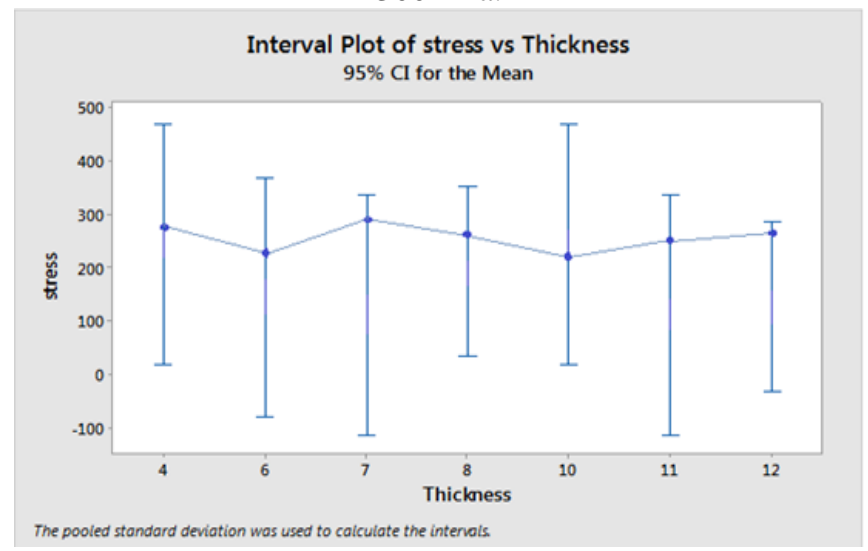

Fig.11 Main effect plot of Stress vs Thickness

\section{CAE ANALYSIS}

The finite element analysis is performed to validate the design of tilting arm and L-joint. The commercially available software ANSYS is used to perform finite element analysis. [8]

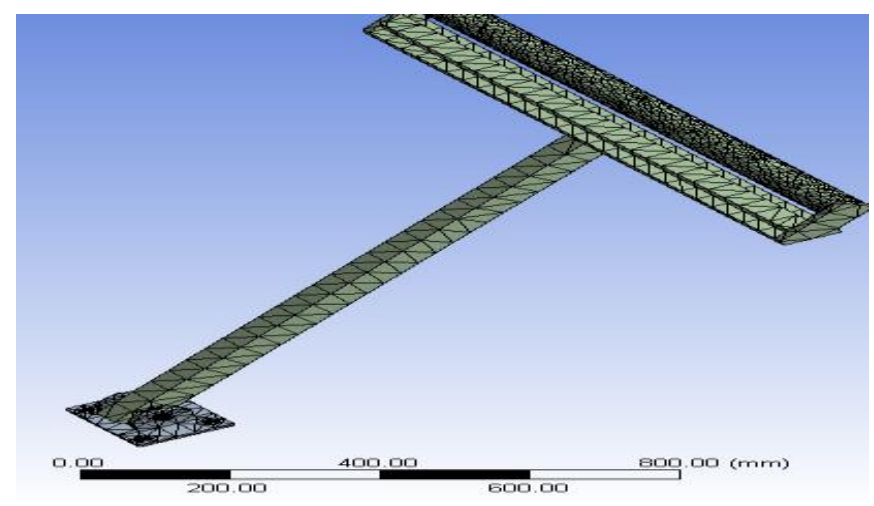

Fig.12. Meshed model of tilting arm

The above Fig.12 shows the meshed model of the tilting arm. Meshing is done using ANSYS workbench. The tilting arm is meshed with 20907 tetrahedral elements.

The boundary conditions applied are shown in the following Fig.13. The bottom plate is fixed and load of 50000 $\mathrm{N}$ is applied on the lifting arm.

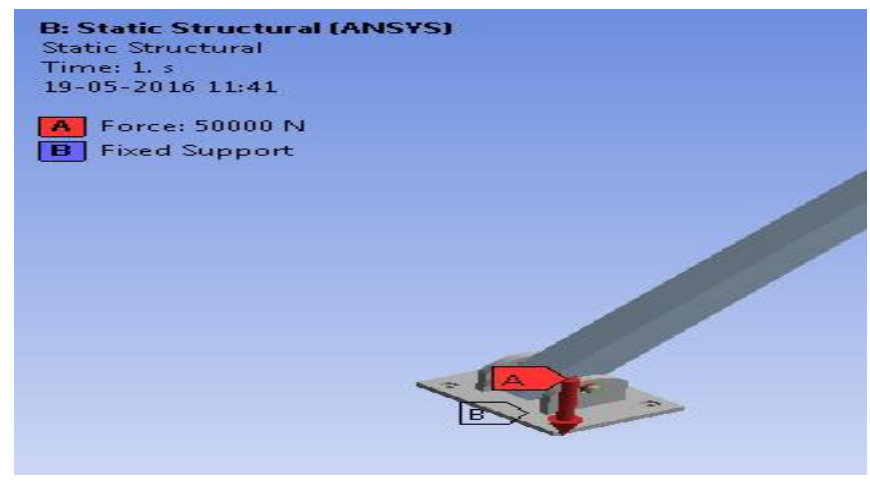

Fig.13. Boundary Conditions 


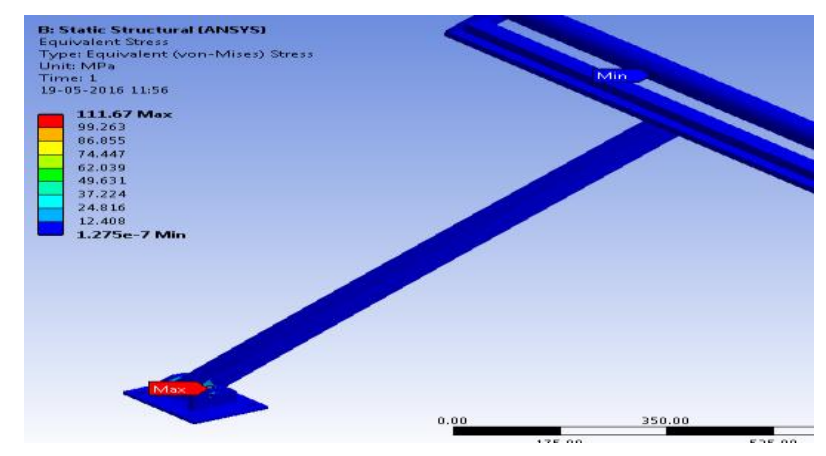

Fig.14. Von-mises stress on lifting arm for 50000N

The finite element simulation shows maximum von-mises stresses at the bottom of the tilting arm. The maximum von-mises stresses shown in Fig. 14 are observed at the bottom of the tilting arm.

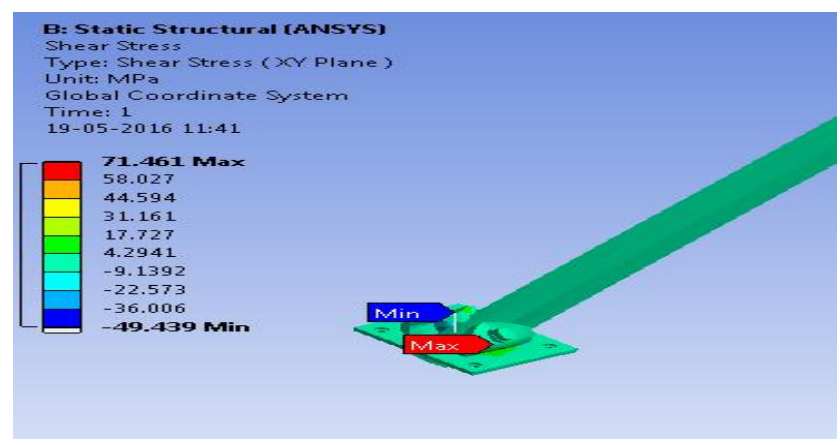

Fig.15. Shear stress occur $71.46 \mathrm{MPa}$

Similarly, in the design of the pin the maximum shear stress obtained by FEA is 71.461MPa as shown in Fig.15. The Fig.16 shows the meshed model of L-bracket. Hexahedral element is used for meshing of L bracket. [9]

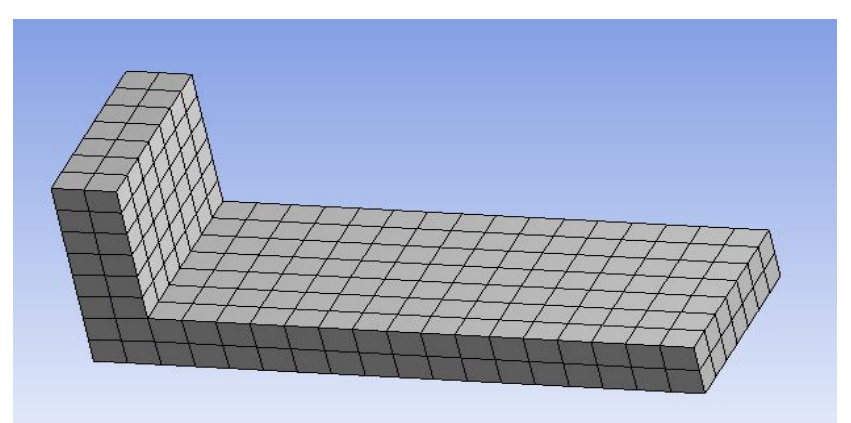

Fig.16. Meshed model of L-Bracket

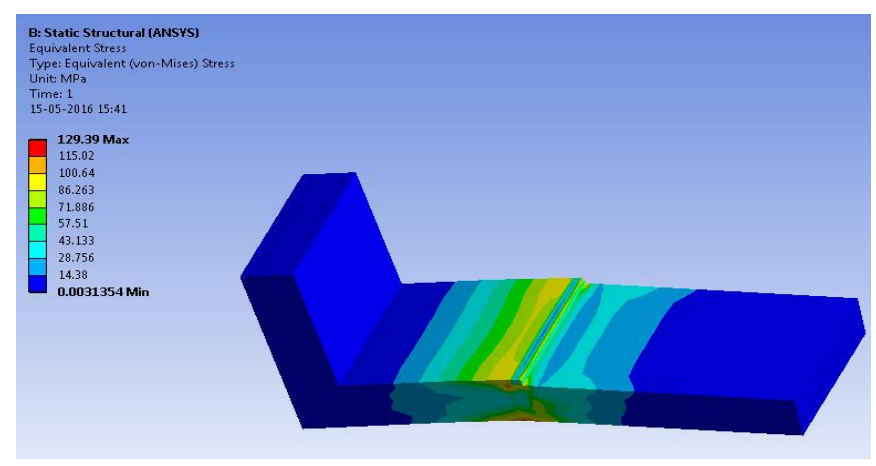

Fig.17. Von-mises stress of 129.39 MPa on L-Bracket 
The finite element simulation shows maximum von-mises stresses on the L-bracket. The maximum von-mises stresses shown in Fig. 17.

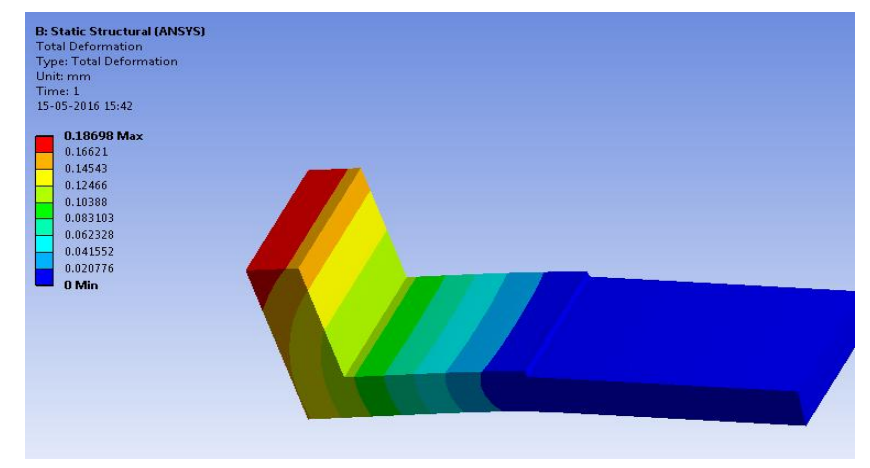

Fig.18. Total deformation of $0.18698 \mathrm{~mm}$

The FEA shows total deformation occurs over the L-Bracket shown in Fig 18.

The comparison of different design stresses obtained by analytical and simulation methods are shown in the

Table 4.

Table 4: Comparison of Analytical and FEA Results

\begin{tabular}{|c|c|c|c|c|}
\hline Component & Parameters & $\begin{array}{c}\text { Design Output } \\
(\mathrm{MPa})\end{array}$ & $\begin{array}{c}\text { CAE Output } \\
(\mathrm{MPa})\end{array}$ & $\begin{array}{c}\% \\
\text { variation }\end{array}$ \\
\hline Strut and Pin & Working Stress & 125 & 111.67 & 10 \\
\hline Pin & Shear Stress & 79.6 & 71.46 & 10.22 \\
\hline L Bracket & $\begin{array}{c}\text { Maximum } \\
\text { Stress }\end{array}$ & 147 & 129 & 12.24 \\
\hline & Deflection & $0.18(\mathrm{~mm})$ & $0.18698(\mathrm{~mm})$ & 3 \\
\hline
\end{tabular}

\section{MODAL ANALYSIS}

A dynamic property of the structure due to vibration response is studied by Modal analysis. Modal analysis is a technique of calculating and analyzing the dynamic response of the components when excited by an input. [10]

7.1 Procedure:

- Our objective is to find out the Natural frequency of the structure so as to check for resonant condition in actual use. Modal analysis is carried out with help of FE analysis software.

- The solid model of Lifting unit is accurately modeled to get close to actual natural frequencies in the simulation.

- A fixed support is given at the bottom of the structure and the analysis is carried out the first six frequencies.

7.2 Meshed model:

Meshed model of the complete structure is as shown in Fig. 19. 


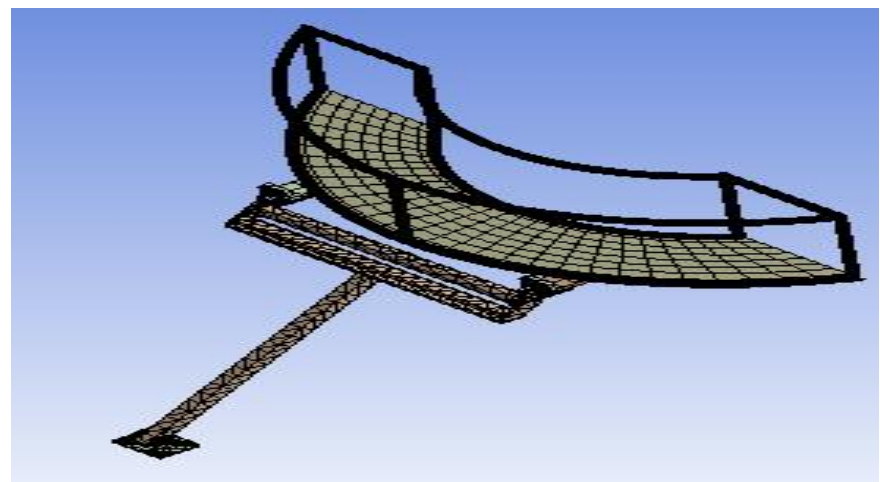

Fig.19 Meshed model of structure

\subsection{Boundary Condition:}

Boundary conditions are applied to the structure as shown in Fig.20. In which fixed support is given at the bottom means at point ' $A$ ' and frictionless support is given at point ' $B$ '.

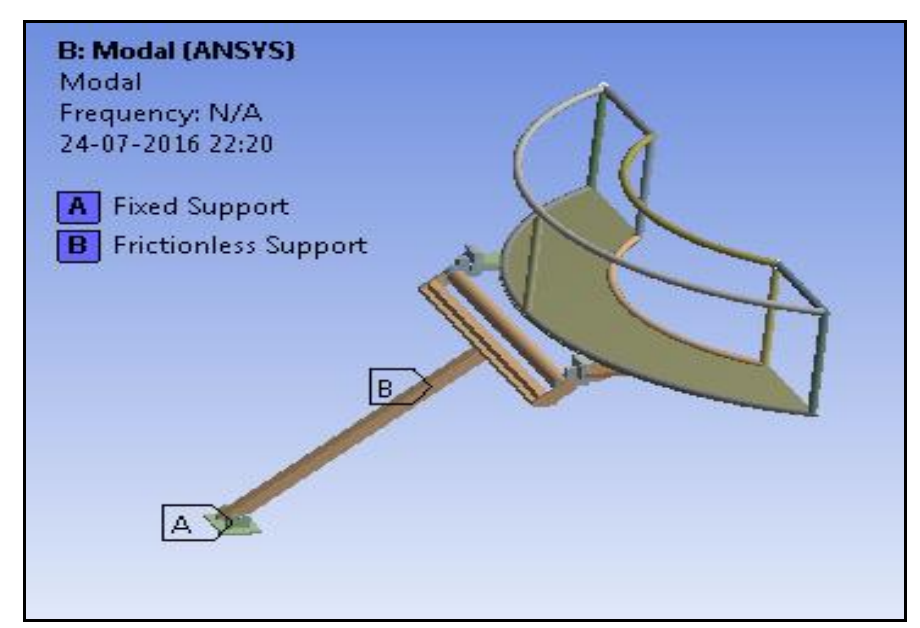

Fig.20 Boundary conditions applied

- Deformation:

After applying the boundary conditions the deformation occurs is as shown in Fig.21.

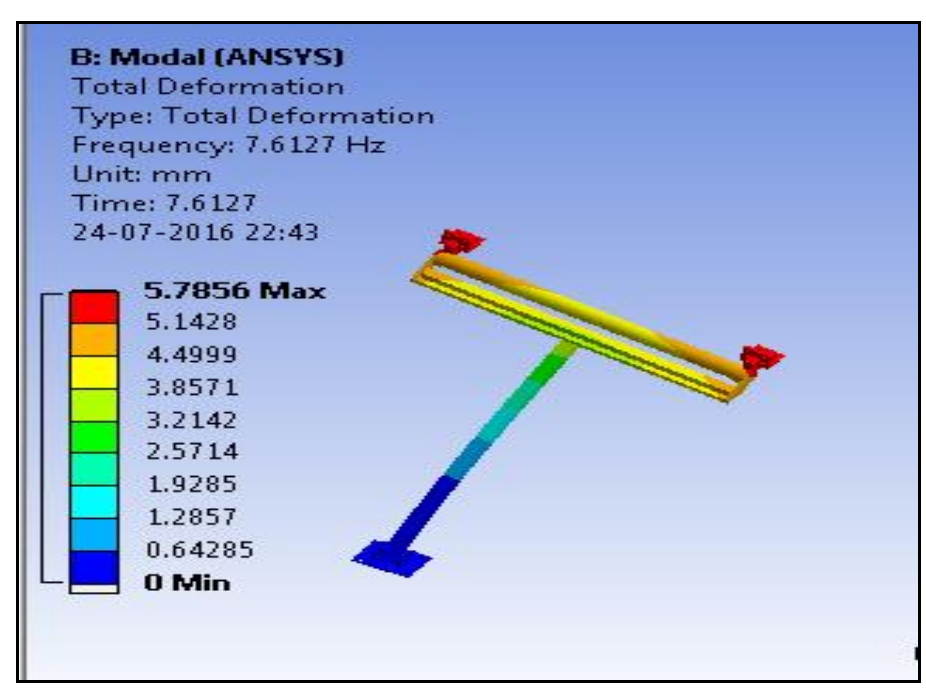

Fig.21 Total deformation

7.4 Modal analysis results:

From the modal analysis, six harmonic frequencies are obtained. These are shown in following Fig.22. 


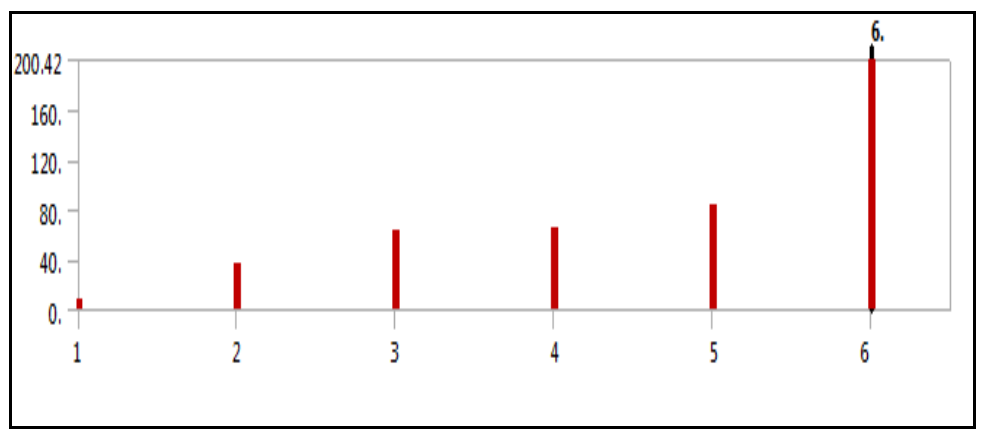

Fig.22 Harmonic frequencies

Results of the Modal analysis from first to sixth harmonic frequency are as shown in Table 5.

Table 5: Modal Results

\begin{tabular}{|c|c|}
\hline Mode & Frequency $(\mathrm{Hz})$ \\
\hline First harmonic frequency & 7.6127 \\
\hline Second harmonic frequency & 36.153 \\
\hline Third harmonic frequency & 63.104 \\
\hline Fourth harmonic frequency & 64.442 \\
\hline Fifth harmonic frequency & 82.944 \\
\hline Sixth harmonic frequency & 200.42 \\
\hline
\end{tabular}

\section{FEA RESULTS AND DISCUSSION}

Johnson's method of material selection yields output as SS 309 to be the best material for the design of the components of the system. The finite element analysis of tilting arm gives $10 \%$ to $15 \%$ variation with the bearing stress obtained by analytical method. In the design of the pin, it gives around $10 \%$ variation with analytical results. Similarly, in design of L-bracket stress variation is up to $12 \%$ and deformation is varying up to $3 \%$.

\section{CONCLUSION}

It is concluded that, as per the processing unit requirement the newly designed semicircular platform can be used to cover maximum area of the pressure vessel for performing the operations. Simultaneously, the Lbracket and arm are useful and critical components in the assembly. They were designed as per the requirement. Manufacturability is also feasible and simple assembly makes its working easier. The results obtained from the analytical methods shows good agreement with CAE results and also it shows that the design is safe under certain accepted parameter.

\section{REFERENCES}

[1] Jaydeep M. Bhatt, et al, Nov.12- Oct. 13, "Design and analysis of an aerial scissor lift", Journal of Information, Knowledge and Research in Mechanical Engineering, ISSN 0975 - 668X, Volume-02, ISSUE -02,452.

[2] T. Islam, et al, "Dynamic analysis of scissor lift mechanism through bond graph modeling" in Proceedings of the IEEE/ASME AI , the IEEE/ASME International Conference on Advanced Intelligent Mechatronics, pp. 1-10, July 7 - 10, Besancon, France 2014.

[3] S.F.Sakore et. al, "Design and structural analysis of lifting arm in processing lift", IOSR, RDME-17.

[4] F. Rahimi Dehgolan, et al, "Obtaining constant of Johnson material model using expt., numerical simulation and optimization method", Jan 1999.

[5] V. Sekar et. al, "Optimising flow stress input for machining simulations using Taguchi methodology”,10.2507/IJSIMM, ISSN 1726-4529, 2012.

[6] S. Athreya et. al, "Application of Taguchi method for optimizing of process parameters in improving the surface roughness", IRJES, ISSN2319-183X, vol-1, Issue-3, Nov-2012.

[7] A.Gelman et. al, "Analysis of Variance" 2005, Vol-33, No-1, 1-53.

[8] Helmi Rashid, et al, "Design Review of Scissors Lifts Structure for Commercial Aircraft Ground Support Equipment using Finite Element Analysis”, 2012.

[9] Veronika Bleaker, et al, "lifting device for scissor lifts" U.S.Patent 0037765 A1, Feb. 14, 2013.

[10] C. Azoury et. al, "Experimental and analytical modal analysis of crankshaft", IOSR, ISSN-22503021,Vol-2, 674-684, April 2012. 